\title{
Targeting Jurkat T Lymphocyte Leukemia Cells by an Engineered Interferon-Alpha Hybrid Molecule
}

\author{
Dehai Yua Zhonghua Duª Wei Lia Huaqiu Chen ${ }^{a}$ Songgen $\mathrm{Ye}^{\mathrm{a}}$ \\ Andrew R. Hoffman ${ }^{b}$ Jiuwei Cui ${ }^{a}$ Ji-Fan Hua,b \\ aStem Cell and Cancer Center, First Hospital, Jilin University, Changchun, China, 'bStanford University \\ Medical School, Palo Alto Veterans Institute for Research, Palo Alto, USA
}

\section{Key Words}

Jurkat-binding peptide $\cdot$ Phage display $•$ Antitumor $・$ Interferon-alpha $•$ Synthetic interferon $•$ Apoptosis $\cdot$ Cell proliferation

\begin{abstract}
Background/Aims: Adult T-cell leukemia/lymphoma (ATL) is a very aggressive T cell malignancy that carries a poor prognosis, primarily due to its resistance to chemotherapy and to lifethreatening infectious complications. Interferon-alpha (IFN $\alpha$ ) has been used in combination with the anti-retroviral drug zidovudine to treat patients with ATL. However, the efficacy of long-term therapy is significantly limited due to the systemic toxicity of IFNa. Methods: We utilized phage display library screening to identify short peptides that specifically bind to Jurkat T lymphocyte leukemia cells. By fusing the Jurkat-binding peptide to the C-terminus of IFN $\alpha$, we constructed an engineered chimeric IFN $\alpha$ molecule (IFNP) for the treatment of ATL. Results: We found that IFNP exhibited significantly higher activity than wild type IFN $\alpha$ in inhibiting the growth of leukemia cells and inducing cell blockage at the G0/G1 phase. The synthetic IFNP molecule exerted its antitumor activity by upregulating the downstream genes involved in the STAT1 pathway and in apoptosis. Using a cell receptor binding assay, we showed that this Jurkat-binding peptide facilitated the binding affinity of IFN $\alpha$ to the cell surface type I IFN receptor. Conclusion: The isolated Jurkat-binding peptide significantly potentiates the therapeutic activity of IFN $\alpha$ in T lymphocyte leukemia cells. The engineered IFNP molecule may prove to a novel antitumor approach in the treatment of patients with ATL.
\end{abstract}

\section{Introduction}

C) 2017 The Author(s)

Published by S. Karger AG, Basel

Adult T-cell leukemia/lymphoma (ATL) is a very aggressive malignancy that is etiologically associated with infection by human T-cell lymphotropic virus type-I (HTLV-I)[1, 2]. Therapeutic interventions, including intensive chemotherapy, are often unsuccessful [3]. Patients have a poor prognosis primarily due to the resistance of leukemic cells to high doses of chemotherapy, large tumor burden, and life threatening infectious complications [4-6].

Ji-Fan Hu, M.D., Ph.D. and Jiuwei Cui 
Combined therapy with interferon-alpha (IFN $\alpha$ ) and the anti-retroviral drug zidovudine (AZT) has been shown to induce responses in patients with ATL [7-9]. Interferons have significant antiviral and anti-proliferative properties. However, the impact of this combined antiviral treatment strategy on long-term survival of ATL patients remains unclear. The potency of long-term IFN $\alpha$ therapy is significantly limited due to its systemic toxicity [10, 11]. Therefore, it is imperative to develop novel therapeutic approaches to treat ATL.

We have previously engineered synthetic interferons by linking the native interferon to a short poly-charged peptide identified by cDNA fragment library screening $[12,13]$. The addition of this poly-charged peptide enhances the binding of interferons to tumor cells, leading to superior tumor-killing activity. In this study, we used phage library screening to identify short peptides that specifically bind to Jurkat T lymphocyte leukemia cells. We reasoned that the Jurkat-binding peptides (JBP), when linked to the C-terminus of IFN $\alpha$, would be able to potentiate the anti-tumor activity of IFN $\alpha$ in patients with ATL. In this study, we used Jurkat T lymphocyte leukemia cell as a disease model to examine whether the synthetic IFN $\alpha$ molecule can be used as an alternative approach for the treatment of ATL.

\section{Materials and Methods}

\section{Cell culture}

Three human cancer cell lines (T lymphocyte leukemia cell line Jurkat, breast cancer MCF7, and prostate cancer PC-3) were purchased from the American Type Culture Collection (ATCC, VA) and routinely cultivated in RPMI-1640 medium (Invitrogen, CA) with 10\% fetal bovine serum (Invitrogen, CA), $100 \mathrm{U} / \mathrm{ml}$ penicillin and $100 \mu \mathrm{g} / \mathrm{ml}$ streptomycin at $37^{\circ} \mathrm{C}$ in a humidified atmosphere containing $5 \% \mathrm{CO}_{2}$. The $293 \mathrm{~T}$ cell line used for lentiviral packaging was purchased from ATCC (Manassas, VA) and cultured in DMEM supplemented with $10 \%$ FBS and $100 \mathrm{U} / \mathrm{ml}$ Penicillin-Streptomycin (Invitrogen, CA).

Phage display library screening of Jurkat binding peptides

Phage display library (Ph.D.-12 library, \#E8110S, New England BioLabs, MA) was used to screen peptides that specifically bind to Jurkat T lymphocyte leukemia cells $[14,15]$. Briefly, $2 \times 10^{9}$ phages in $1 \mathrm{ml}$ RPMI-1640 medium were incubated with $1 \times 10^{6}$ Jurkat cells for $1 \mathrm{hr}$ at room temperature. The phage-cell complexes were further incubated at $37^{\circ} \mathrm{C}$ for $30 \mathrm{~min}$ to allow phagocytosis to occur. After binding, cells were washed 5 times with $5 \mathrm{ml}$ TBST [TBS $(10 \mathrm{mmol} / \mathrm{l}$ Tris $\mathrm{pH} 7.5,150 \mathrm{mmol} / \mathrm{l} \mathrm{NaCl})$ containing $0.1 \%$ Tween 20] to remove the unbound and non-phagocytosed phages. Cells were collected by centrifuge at $3200 \mathrm{~g}$ for $5 \mathrm{~min}$. The surface-bound phages were eluted for $20 \mathrm{~min}$ at room temperature with $1 \mathrm{ml}$ elution buffer [0.2 M Glycine- $\mathrm{HCl}(\mathrm{pH}$ 2.2), $1 \mathrm{mg} / \mathrm{ml} \mathrm{BSA}$ ] and then neutralized with $150 \mu \mathrm{l} 1 \mathrm{M}$ Tris- $\mathrm{HCl}, \mathrm{pH}$ 9.0. The Jurkat cell-internalized phages were released by lysing the cells in lysis buffer $(1 \mathrm{mM}$ triethylamine with $0.5 \%$ Triton X-100) for $1 \mathrm{~min}$ at RT and then immediately neutralizing the solution to $\mathrm{pH} 7.4$ with $10 \times \mathrm{PBS}$ premixed with diluted $\mathrm{HCl}$ [16]. Both surface-bound and phagocytosed phages were infected into E. coli ER2738 and then purified using PEG 8000/NaCl solution.

After4 roundsofsurfacepanning, theDNAsequenceofJurkat-bindingpeptides(JBP)wasamplified by PCR (Fig. 1A). Primers used for PCR amplification were as follows: 5'-CTTTAGTGGTACCTTTCTATTCTCGAGTCT-3' (forward primer with Xhol) and 5'-CTTTCAACAGTTTCGTCTAGAACCTCCACC-3' (reverse primer with Xbal). The phage peptides were cloned into pJet vector using CloneJET PCR Cloning Kit (Thermo Fisher Scientific, CA) and sequenced for constructing engineered IFN $\alpha$ molecules.

\section{Phage-ELISA assay}

An ELISA assay was used to compare the binding affinity of the isolated Jurkat-binding peptides. About $2 \times 10^{4}$ Jurkat cells in 96 well V-bottom plate were incubated with block buffer ( $5 \%$ BSA/PBS, Sigma) for $1 \mathrm{hr}$ at $37^{\circ} \mathrm{C}$. For comparison, MCF7 breast cancer and PC-3 prostate cancer cells were used as controls. Cells were pelleted by centrifuge at $3200 \mathrm{~g}$ and resuspended in $100 \mu \mathrm{l}$ PBS buffer containing $1 \times 10^{10}$ phage particle. After incubation at RT for $1 \mathrm{hr}$, cells were pelleted by centrifuge at $3200 \mathrm{~g}$ and washed with PBST for $5 \times 5$ min. For quantitation, cells were incubated with $100 \mu \mathrm{l}$ PBS buffer containing HRP conjugated anti-M13 monoclonal antibody $(1: 5000, \mathrm{GE}, \mathrm{NJ}, \mathrm{USA})$ at $37^{\circ} \mathrm{C}$ for $45 \mathrm{~min}$. Cells were centrifuged at $3200 \mathrm{~g}$ 


\section{Cellular Physiology Cell Physiol Biochem 2017;42:519-529 \begin{tabular}{l|l|} 
and Biochemistry Published on/ne: June 02, 2017 & $\begin{array}{l}\text { C } 2017 \text { The Author(s). Published by S. Karger AG, Basel } \\
\text { www.karger.com/cpb }\end{array}$
\end{tabular}}

Yu et al.: Antitumor Activity of IFNa-JBP

and washed with PBST for $5 \times 5$ min. Then $100 \mu$ of TMB solution (BD, CA, USA) was added to each well and the plate was kept in the dark for $\sim 15$ min until a blue color developed. The reaction was stopped by adding $50 \mu \mathrm{l} 1 \mathrm{~N}$ sulfuric acid. Final optical density was read at 450-650 $\mathrm{nm}$ on a microplate reader (Bio-Rad, CA, USA).

\section{Recombinant plasmids and lentivirus production}

After library screening and sequencing, one of the Jurkat cell-binding peptides (JBP) was selected. We ligated this peptide to the C-terminus of INF $\alpha$ to construct an engineered INF $\alpha$ fusion protein. The expression plasmid for the wild type IFN $\alpha$ was prepared as previously described [12,13]. The synthetic interferon construct was generated by ligating the JBP sequence into the IFN $\alpha$ vector at the XhoI/XbaI restriction sites, and was designated as IFNP. The empty lentivirus vector and the vector containing the isolated JBP were used as control groups for the study. All constructs were confirmed by DNA sequencing. The putative structure of the IFNP was predicted using the online I-TASSER server (http://zhanglab.ccmb. med.umich.edu).

We used lentivirus vectors containing a green fluorescent protein (copGFP) gene to track lentiviral infection. Lentiviruses were packaged by the co-transfection of the constructed plasmids and pSPAX2/ pMD2G packing vectors using lipofectamine 2000 (Invitrogen, CA). The viral supernatants were collected at $48 \mathrm{~h}$ and $72 \mathrm{~h}$ post-transfection and used for cell transfection as previously described $[17,18]$.

\section{Infection of recombinant lentivirus}

Jurkat cells were plated at a density of $5 \times 10^{5} / \mathrm{ml}$ in six-well plate $24 \mathrm{hrs}$ pre-transfection. Cells were infected with lentiviruses containing IFNP, INF $\alpha$, JBP, and empty vector in the presence of $4 \mu \mathrm{g} / \mathrm{ml}$ polybrene (Sigma, MO). After incubation at $37^{\circ} \mathrm{C}$ for $24 \mathrm{hrs}$, the medium was replaced with a fresh medium in the absence of polybrene. Three days following viral infection, cells were selected by puromycin and copGFPpositive stable cells were used for this study.

\section{Cell viability determination by the CCK8 assay}

Equal amount of stable Jurkat cells $\left(5 \times 10^{3}\right)$ were plated in 96-well plates and cultured for 48 hrs. For the cell viability assay, $10 \mu \mathrm{l} \mathrm{CCK-8} \mathrm{solution} \mathrm{(Thermo,} \mathrm{Beijing,} \mathrm{China)} \mathrm{was} \mathrm{added} \mathrm{to} \mathrm{each} \mathrm{well} \mathrm{and} \mathrm{the} \mathrm{plate}$ was incubated at $37^{\circ} \mathrm{C}$ for $2 \mathrm{hrs}$. The absorbance at $450 \mathrm{~nm}$ was measured using microplate reader (Bio-rad, PA)[19].

To examine the contribution of IFBP in co-treatment with Zidovudine, equal amount of stable Jurkat cells $\left(1 \times 10^{4}\right)$ were plated in 96-well plates and were treated with a low dose of zidovudine (AZT, $\left.5 \mu \mathrm{M}\right)$ for 48 hours. Cell viability was determined by the CCK8 assay.

\section{Cell cycle analysis}

After puromycin selection, stable Jurkat cells were collected and washed twice by $1 \mathrm{ml}$ cold PBS. Cells were pelleted and resuspended in $1 \mathrm{ml}$ fixation solution (300 $\mu \mathrm{l}$ PBS and $700 \mu \mathrm{l}$ ethanol). After incubation at $4^{\circ} \mathrm{C}$ for $4 \mathrm{hrs}$, cells were centrifuged at $1000 \mathrm{rpm}$ for $5 \mathrm{~min}$ and fixation solution was removed. After two washes with $1 \mathrm{ml} \mathrm{PBS}$, the cells were pelleted and suspended in $0.5 \mathrm{ml}$ propidium iodide staining solution (50 $\mu \mathrm{g} / \mathrm{ml} \mathrm{PI,} 20 \mu \mathrm{g} / \mathrm{ml}$ RNase A and $0.2 \%$ Triton X-100) and incubated in the dark at $37^{\circ} \mathrm{C}$ for $30 \mathrm{~min}$. Cell suspensions were filtered through a 400-mesh sieve and were analyzed using a BD FACSCalibur flow cytometer (Becton Dickinson, Sparks, MD)[20].

Gene expression by RT-PCR

Total RNA was extracted from Jurkat cells using the Trizol reagent (Invitrogen, CA). After removing the residual genomic DNA with DNase I (Invitrogen, CA), M-MLV Reverse Transcriptase (Invitrogen, CA) was used to synthesize cDNA [17, 21]. The mRNA expression level of ADPR, MX1, IFIT1, OAS2, P21, and CASPAS3 was quantified by normalizing over $\beta$-actin. The primers used for RT-PCR include: 1). ADPR-V1, JH2557 (forward): 5'-CAATGAATCCGCGGCAGGGGT-3' and JH2558 (reverse): 5'- TCTGGGATCTGCCCCTTGAG-3'; 2). MX1, JH2769 (forward): 5'-CASTATGAGGAGAAGGTGCG-3' and JH2770 (reverse): 5'CAGCACCAGMGGGCATCTGGT-3'; 3). IFIT1, JH2767 (forward): 5'-GCTGCCWMMTTTACAGCAACCATG-3' and JH2768 (reverse): 5'-CAGGCAMAGTTGCCCCAGGTC-3'; 4). OAS2, JH2771 (forward): 5'-GWKGGTWTATCCAGGAAWACCT-3' and JH2772 (reverse):5'-GRACAAGGGTACCATCGGAG-3'; 5).P21, JH839 


\section{Cellular Physiology Cell Physiol Biochem 2017;42:519-529 \\ \begin{tabular}{l|l} 
and Biochemistry Published onIne: June 02, 2017 & $\begin{array}{l}\text { C } 2017 \text { The Author(s). Published by S. Karger AG, Basel } \\
\text { www.karger.com/cpb }\end{array}$
\end{tabular}}

Yu et al.: Antitumor Activity of IFN $\alpha-J B P$

(forward): 5'-GTGGACCTGTCACTGTCTTGTAC-3' and JH840 (reverse): 5'-GCTTCCTCTTGGAGAAGATCAGC-3'; 6). Caspase3, JH2629 (forward): 5'-ATGGAGAACACTGAAAACTCAG-3' and JH2630 (reverse): 5'-CAGACCGAGATGTCATTCCAG-3'.

Protein extraction and Western blot analysis

Cell total protein was extracted with RIPA buffer (Beyotime Biotechnology, Shanghai, China) supplemented with cocktail protease inhibitor (Roche), and the protein concentration was determined by a BCA protein assay kit (Beyotime Biotechnology, Shanghai, China). Twenty microgram total protein were separated by 5\%-12\% SDS polyacrylamide gel electrophoresis (SDS-PAGE) and were electrophoretically transferred to PVDF membranes ( $0.45 \mu \mathrm{m}$, Millipore, Billerica, MA, USA). After blocking with 5\% skim milk in TBST [TBS (10 mmol/l Tris pH 7.5, $150 \mathrm{mmol} / \mathrm{l} \mathrm{NaCl}$ ) containing $0.1 \%$ Tween 20] at $37^{\circ} \mathrm{C}$ for $1 \mathrm{~h}$, the membranes were incubated with monoclonal antibodies against p21 (Santa Cruz Biotechnology, Santa Cruz, CA, USA), caspase 3 (Cell Signaling Technology, Beijing, China), STAT1 (Abcam, Shanghai, China), and $\beta$-ACTIN (Santa Cruz Biotechnology) at $4^{\circ} \mathrm{C}$ overnight. After washing for $3 \times 5$ min with TBST, the membranes were incubated with HRP-conjugated goat anti-mouse or goat anti-rabbit second antibodies (ZSGB-BIO, Beijing, China) at $37^{\circ} \mathrm{C}$ for $1 \mathrm{~h}$. The immunocomplexes were detected with the enhanced chemiluminescence system (ECL, Thermo, Beijing, China) and X-ray film (Kodak, Beijing, China). Protein expression levels were determined semi-quantitatively by densitometric analysis with the Quantity One software (Bio-Rad, CA) $[20,22]$.

For the detection of the secreted IFN $\alpha$ and IFNP proteins in cell supernatants, the supernatants were collected from stable Jurkat cells and $20 \mu \mathrm{l}$ was separated on Mini-PROTEIN TGX gradient gel for Western detection using anti-IFN $\alpha$ antibody (Abcam, Shanghai, China).

Cell binding assay of IFNP

The binding of the engineered interferon to the Jurkat cell membrane receptor was compared using FACS. Jurkat cells were collected and stained with Trypan blue to make sure that there were $>90 \%$ viable cells. Cells $\left(1 \times 10^{6}\right.$ cells/tube in PBS $)$ were incubated with equal amounts of the secreted IFNP and IFN $\alpha$ for $1 \mathrm{~h}$ at $37^{\circ} \mathrm{C}$. After washing with PBS, the cells were incubated with FITC-conjugated IFN $\alpha$ antibody (PBL, NJ), according to the manufacture's instruction. The FITC-conjugated mouse IgG (Abcam, MA) was used as the isotype control. Cells were analyzed using LSRFortessa (BD Biosciences, CA) and FlowJo software (FlowJo, OR, USA) to calculate the fluorescence intensity $[12,13]$.

Statistical analysis.

All experiments were performed in triplicate and the data were expressed as mean \pm SD. The significance was determined by Student's $t$ test using SPSS 20.0 (IBM). $P<0.05$ was considered statistically significant.

\section{Results}

Construction of the IFN $\alpha$-JBP hybrid molecule

To enhance the antitumor activity of IFN $\alpha$ in the ATL therapy, we first used a phage library display system to identify short peptides that specifically bind to Jurkat leukemia cells (Fig. 1A). We hypothesized that the addition of a short, high-affinity peptide to the C-terminus of IFN $\alpha$ would be able to facilitate the binding of IFN $\alpha$ to Jurkat cell membranes, where the cytokine exerts its cell killing activity. We were particularly interested in short peptides that could induce phagocytosis in Jurkat cells.

To screen for high affinity peptides, Jurkat cells were incubated briefly with the phage library. Unphagocytosed surface-bound phages were stripped off by stripping buffer. The phagocytosed phages were recovered for the second round of phage display screening. After five rounds of screening, we identified phages that were specifically enriched in Jurkat cells. Through cloning and sequencing, we selected one phage that encodes an "eat-me" peptide for further study (Fig. 1B). Using ELISA, we showed that this eat-me peptide was able to bind preferentially to Jurkat T lymphocyte leukemia cells as compared with MCF7 breast cancer 


\section{Cellular Physiology Cell Physiol Biochem 2017;42:519-529 \begin{tabular}{l|l} 
DOI: 10.1159/000477601 & O 2017 The Author(s). Published by S. Karger AG, Basel \\
www.karger.com/cpb
\end{tabular} Yu et al.: Antitumor Activity of IFNa-JBP}

Fig. 1. Construction of the IFN $\alpha /$ Jurkat-binding peptide fusion protein. (A) Phage-display library screening of the leukemia cell-binding peptides. Jurkat leukemia cells were incubated with phage display libraries (\#E8110S, NEB) and the Jurkat-specific binding phages were screened following the manufacturer's protocol. After 5 rounds of surface panning, DNA sequences encoding the Jurkat leukemia cell-binding peptides were cloned and sequenced. (B) The amino acid sequence of the Jurkat leukemia cell-binding peptide (JBP) selected for this study. (C) Binding of the JBP-carrying phage. JBP-phage was incubated with tumor cells. After washing, the binding of JBP phage to the cells was quantitated with ELISA kit. * $\mathrm{p}<0.01$ compared with MCF-7 and PC-3 tumor cells. (D) Synthetic IFN $\alpha$ vector constructs. pCMV: CMV promoter; IFN $\alpha$ : wild type interferon alpha; IFNP: synthetic interferon alpha (IFN $\alpha$-JBP); BP: the control construct that contains only JBP; vector: vector control. (E) The predicted protein structure of the synthetic IFNP. The putative structure of IFNP was predicted using the software on the website: http://zhanglab.ccmb.med.umich.edu.

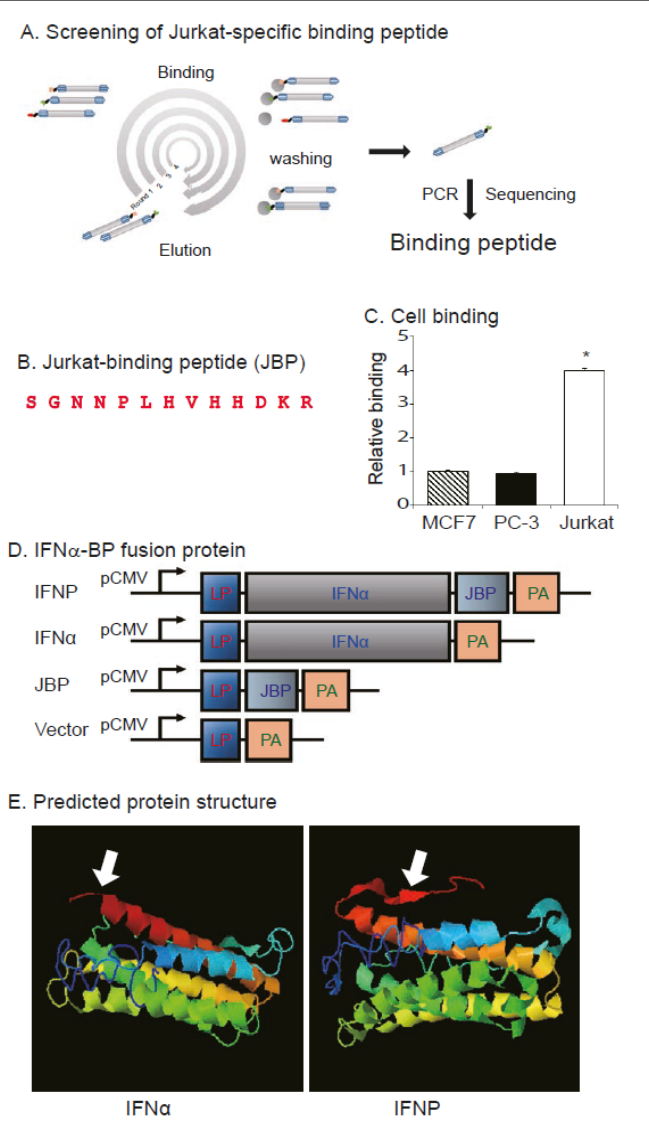

and PC3 prostate cancer cells (Fig. 1C). A public website blast search did not reveal any homologs in the protein databases.

To examine the role of this short peptide, we synthesized an IFN $\alpha$ hybrid molecule (IFNP) by linking the peptide to the C-terminus of IFN $\alpha$ (Fig. 1D) and comparing the antitumor activity of IFNP with the wild type IFN $\alpha$ construct. Figure 1E shows the predicted protein structure of the synthesized IFNP molecule.

IFNP inhibits growth of Jurkat leukemia cells

We then compared the role of the synthetic IFNP with the wild type IFN $\alpha$ in inhibition of cell proliferation. Jurkat cells were transfected with lentiviruses carrying IFNP, IFN $\alpha$, JBP control, and the vector, respectively, and were compared for their proliferative activity. Both IFNP and IFN $\alpha$ inhibited cell growth, but IFNP was superior to IFN $\alpha$ (Fig. 2A). By assessing cell viability, we found that IFNP induced a greater inhibition of cell growth than did IFN $\alpha$ (Fig. 2B, p<0.01). Similarly, when co-treated with a low dose of Zidovudine (5 $\mu$ M), IFBP exhibited the best therapeutic effect among treatment groups (Fig. 2D).

\section{IFNP induces the G0/G1 blockage}

It has been shown that IFN- $\alpha$ induced cell cycle arrest and cell apoptosis in HTLV-1infected T-cells that were collected from patients with ATL [23]. Given the fact that IFNP inhibits the growth of Jurkat cells, we used FACS to examine whether IFNP functions by affecting cell cycle. Stable Jurkat cells were collected and subjected to cell cycle analysis. The vector control and the JBP peptide control did not significantly affect the cell cycle. However, both IFNP and IFN $\alpha$ blocked Jurkat cells at the G1 stage, leading to the reduction of the number of tumor cells in S phase (Fig. 3). However, IFNP showed a significantly better effect than IFN $\alpha$ in reducing the $\mathrm{S}$ phase population of Jurkat cells. 
Fig. 2. The synthetic IFNP molecule inhibits cell proliferation of Jurkat leukemia cells. (A) Expression of the synthetic interferon in Jurkat leukemia cells. Forty-eight hours after viral infection, cells were selected by puromycin. Supernatants $(20 \mu \mathrm{l})$ from Jurkat cells were collected and separated on Mini-PROTEIN TGX gradient gel for Western blot analysis. IFNP: $23.1 \mathrm{kD}$, IFN $\alpha$ : $21.6 \mathrm{kD}$ as estimated by ExPASy (http://web.expasy.org/cgi-bin/compute_pi/ pi_tool). (B) Inhibition of Jurkat leukemia cell growth. Jurkat leukemia cells were transfected with lentiviruses carrying IFN $\alpha$, IFNP, BP, and vector control. PBS was used as a negative control. Photos were taken on day 7 after viral transduction. (C) Cell viability in Jurkat leukemia cells. Cells were collected on day 7 following lentiviral transfection. $*$ p $<0.05$ as compared with controls and with the IFN $\alpha$ group. All data shown are mean \pm SD from three independent assays. (D) Co-treatment with Zidovudine. Jurkat cells that stably expressed interferons were co-treated with a low dose of zidovudine (AZT, $5 \mu \mathrm{M})$. The cell viability was determined by the CCK8 assay. $* \mathrm{p}<0.05$ as compared with control groups.

Fig. 3. IFNP induces $S$ phase blockade in Jurkat leukemia cells. Jurkat leukemia cells were transfected with interferon lentiviruses. Forty-eight hours after viral infection, cells were selected by puromycin. Stable cells were collected and submitted to cell cycle analysis (A-E). Three independent cell cycle analyses were performed and averaged for each treatment group (F). $* \mathrm{p}<0.05$ as compared with the wild type IFN $\alpha$ group.

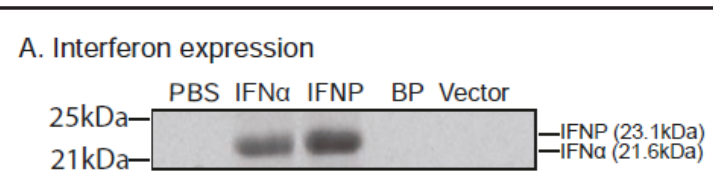

B. Jurkat cell mophorlogy
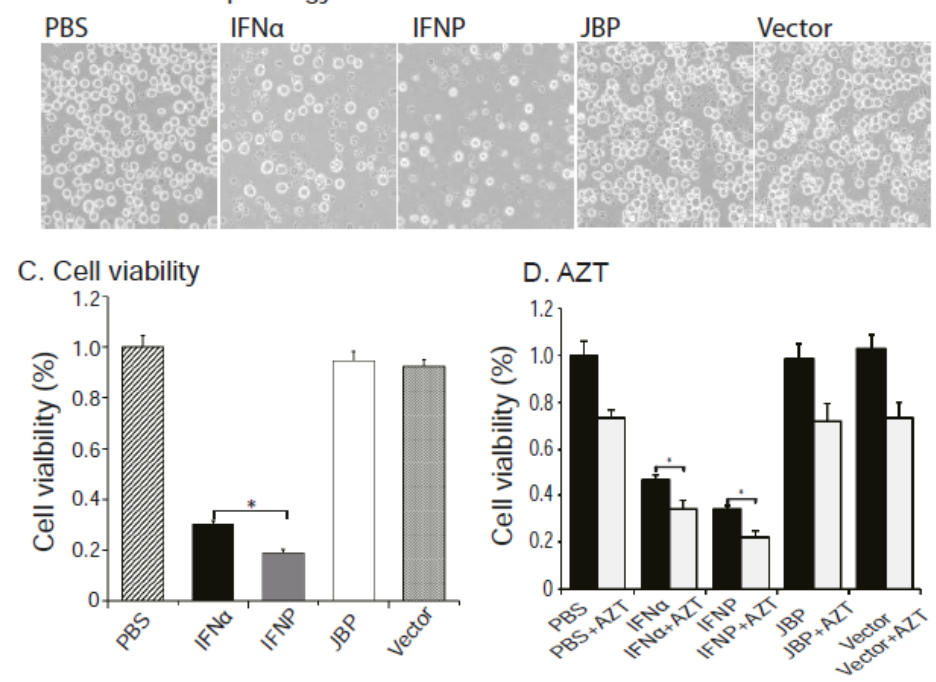

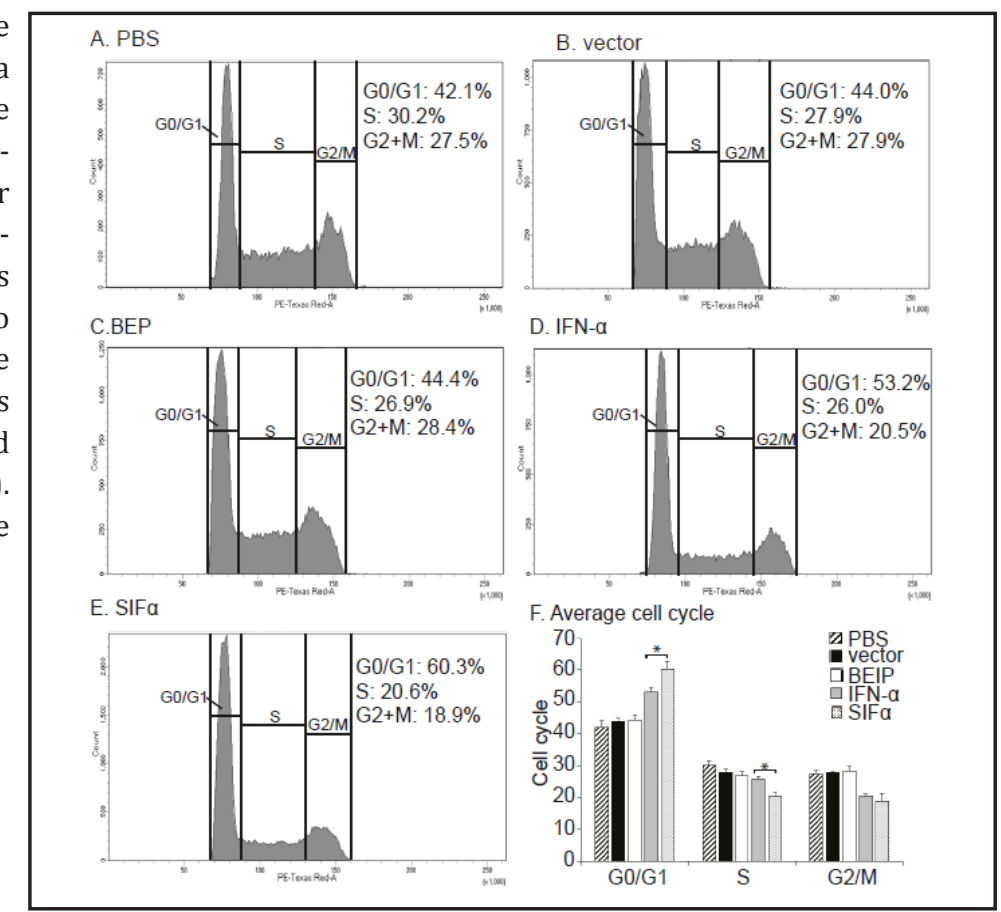

Activation of the STAT1 pathway by IFNP

To delineate the mechanism underlying this enhanced activity by IFNP, we used RT-PCR to examine the expression of interferon pathway genes in the treated cells. We observed that 


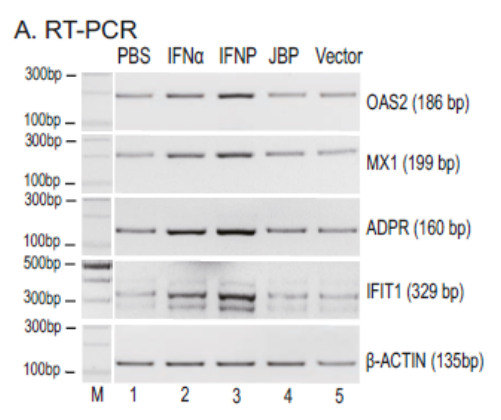

C. Quantitative PCR
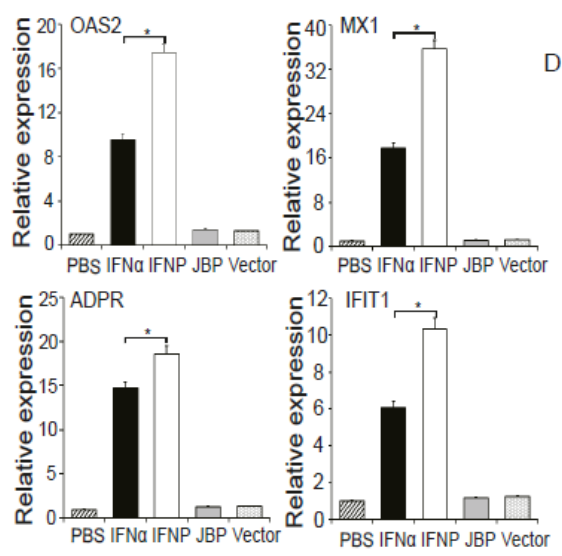
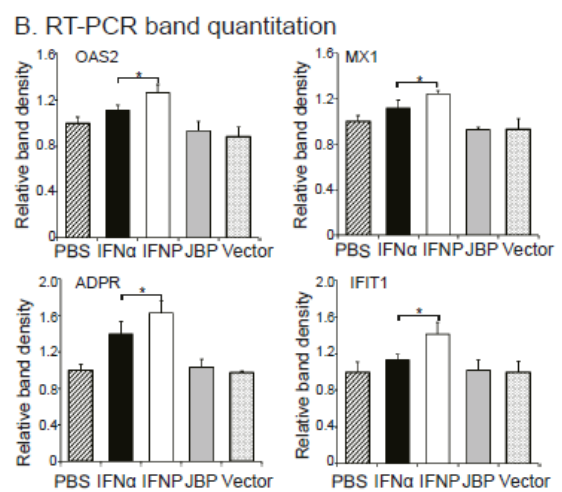

D. Western blot
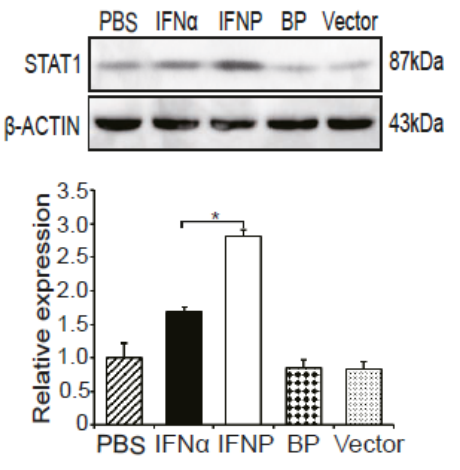

Fig. 4. IFNP activates the STAT1 signal pathway. (A) RT-PCR of the STAT1 signal pathway genes. Stable Jurkat leukemia cells were collected and total RNA was extracted for the measurement of the STAT1 pathway genes by RT-CPR. $\beta$-ACTIN was used as the internal control for PCR reaction. (B) elative band density of RT-PCR. * $\mathrm{p}<0.01$ as compared with the wild type IFN $\alpha$ group. (C) Quantitative analyses of the activation of the STAT1 signal pathway. All data shown are mean \pm SD from three independent. ${ }^{*} \mathrm{p}<0.05$ as compared with the PBS control and with the wild type IFN $\alpha$ group. (D) Western blot of STAT1 protein. After puromycin selection, stable cells were collected for Western blot analysis. Top panel: Western blot image; bottom panel: Western blot density quantitation. ${ }^{*} \mathrm{p}<0.05$ as compared with the PBS control and with the wild type IFN $\alpha$ group.

both IFNP and IFN $\alpha$ upregulated several genes in the interferon pathway, including OAS2, MX1, ADPR, and IFIT1 (Fig. 4A). Semi-quantitation of PCR band density showed that IFNP had a better effect than IFN $\alpha$ in activating the interferon pathway (Fig. 4B). Similar data were also obtained in Jurkat cells using quantitative PCR (Fig. 4C). The activation of the STAT1 pathway was also confirmed using Western blot (Fig. 4D).

Upregulation of the apoptosis pathway by IFNP

We also examined the genes that related to apoptosis in the IFNP-treated cells. Using PCR, we showed that IFNP significantly upregulated Caspase 3 and p21 in Jurkat cells (Fig. $5 \mathrm{~A}, 5 \mathrm{~B})(\mathrm{p}<0.01)$. The activation of the apoptosis pathway was also confirmed in the IFNPtransfected Jurkat cells using Western blotting (Fig. 5C, 5D).

The enhanced binding of IFNP to the membrane of Jurkat cells

IFN $\alpha$ exerts its function through the binding and interaction with the specific cell surface type I IFN receptor. We assessed whether the binding of the synthetic IFN $\alpha$ to Jurkat cells was increased by addition of the phage peptide JBP. Using FACS, we showed that IFNP bound significantly better than IFN $\alpha$ to Jurkat cells (Fig. 6). These data suggest that the phage peptide enhances the antitumor effect by increasing the affinity of the cytokine to the cell membrane. 
Fig. 5. The IFN $\alpha$-engineered protein induces cell cycle arrest and activates the apoptosis pathway. (A) RT-PCR of the cell cycle arrest and apoptosis pathway genes in Jurkat leukemia cells. $\beta$-ACTIN was used as the internal control for PCR reaction. (B) Relative band density of RT-PCR. * p $<0.01$ as compared with the wild type IFN $\alpha$ group. (C) Western blot of the cell cycle arrest and apoptosis pathway genes in Jurkat leukemia cells. $\beta$-ACTIN was used as the internal control for blotting reaction. (D) Relative band density of western blot. $* \mathrm{p}<0.01$ as compared with the wild type IFN $\alpha$ group.

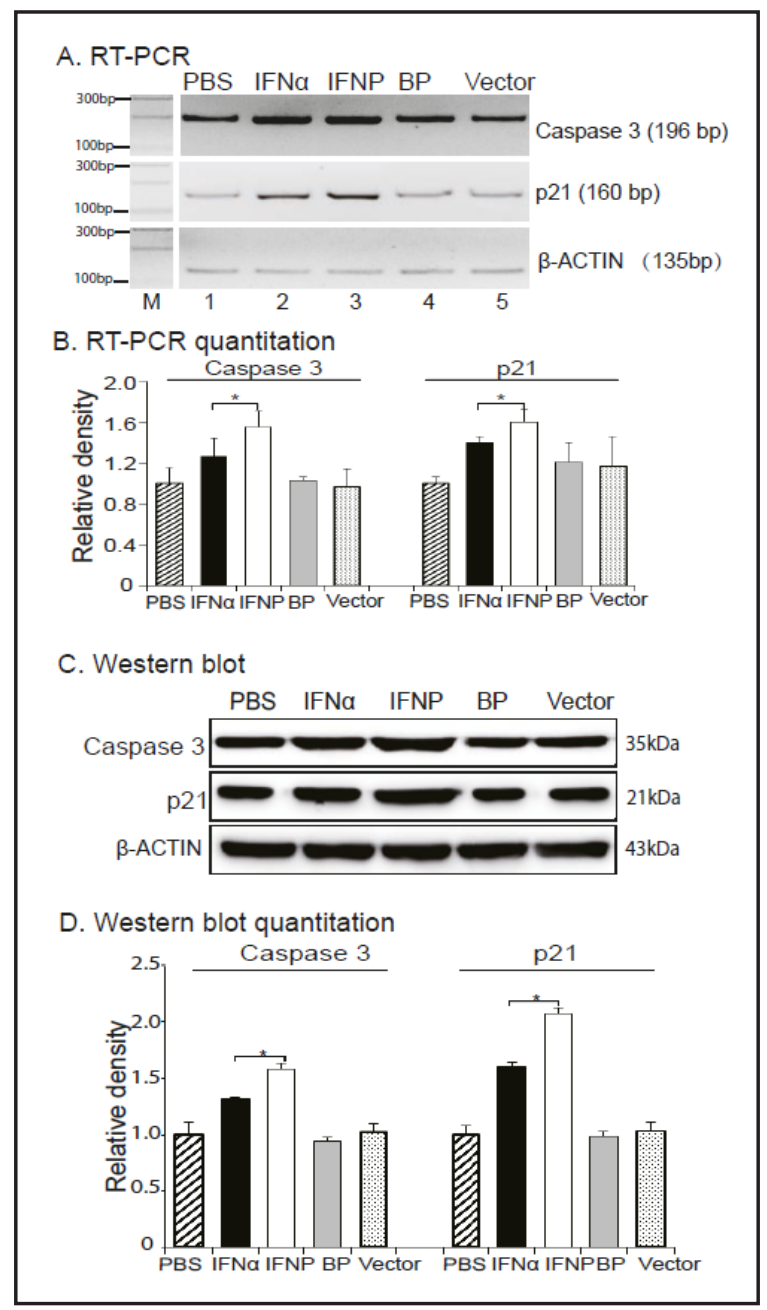

Fig. 6. The Jurkat-phage peptide enhances the binding of IFN $\alpha$ to the cell surface of Jurkat leukemia cells. (A) The FACS cell binding assay. Jurkat leukemia cells were incubated with cell supernatants containing the synthetic interferon. The FITC conjugated-IFN $\alpha$ antibody was used for quantitation of the cell binding. The FITC mouse IgG was used as the isotype control. The fluorescence intensity was calculated to evaluate the cell binding. (B) Fluorescence intensity in IFNP- and IFN $\alpha$-treated cells. Fluorescence in-

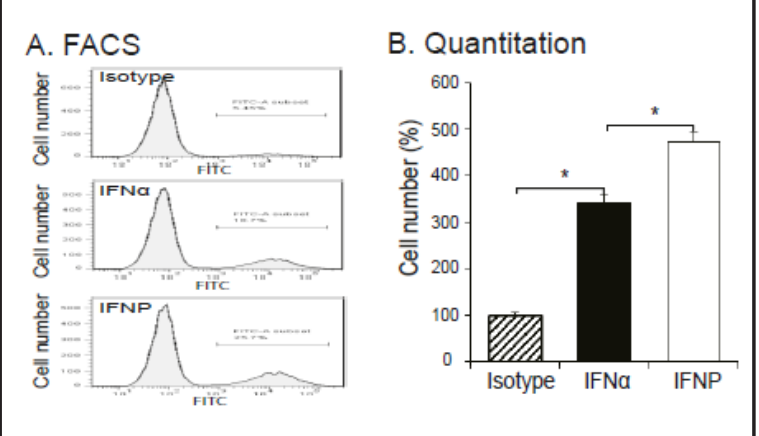
tensity was standardized as the percentage of the isotype control group. Data represent mean \pm SD of three independent repeats. * Significantly higher binding to the Jurkat cancer cells $(\mathrm{p}<0.05)$.

\section{Discussion}

The combination of IFN $\alpha$ and AZT has been used to treat patients with ATL, but longterm therapy is limited due to the relatively low potency and systemic toxicity of IFN $\alpha$. In this communication, we have identified a short peptide (JBP) that specifically binds to Jurkat T lymphocyte leukemia cells. By fusing this Jurkat-binding peptide to the C-terminus of IFN $\alpha$, we demonstrate that the engineered IFNP molecule has significantly better antitumor activity 


\section{Cellular Physiology Cell Physiol Biochem 2017;42:519-529 \\ \begin{tabular}{l|l} 
and Biochemistry Published online: June 02, 2017 & $\begin{array}{l}\text { D } 2017 \text { The Author(s). Published by S. Karger AG, Basel } \\
\text { www.karger.com/cpb }\end{array}$
\end{tabular} \\ Yu et al.: Antitumor Activity of IFN $\alpha$-JBP}

than the wild type IFN $\alpha$. IFNP induces cell blockage at the G0/G1 phase by upregulating the STAT1 and apoptosis pathways. Thus, this engineered IFN $\alpha$-JBP molecule may serve as a novel antitumor agent in the treatment of patients with ATL.

The specific molecular mechanism underlying the enhanced antitumor effects of IFNP is still unknown. Using a cDNA in-frame library screening approach, we recently identified a short peptide derived from placental growth factor-2 (PLGF-2). Fusion of this short peptide to the C-terminus of IFN $\alpha$ and IFN $\gamma$ induced significantly greater activity than did the wildtype counterparts in the inhibition of tumor cell growth, cell invasion and tumor colony formation $[12,13]$. It is noteworthy that the PLGF-2 peptide is rich in positively charged amino acids, with 11 arginine (K) and lysine (L) residues at its $\mathrm{N}$-terminus. The potentiation of interferon antitumor activity by this short PLGF-2 PCP peptide is related to its positively charged amino acids $[12,13]$. However, the Jurkat-binding peptide isolated in this study is not positively charged and it contains only a single arginine (K)(Fig. 1B). The Jurkat-binding peptide may function using a distinct mechanism to enhance the activity of the interferon.

The activity of cytokines is orchestrated by their binding to the extracellular matrix (ECM) of the target cell [24]. For example, the extracellular matrix-bound IFN $\alpha$ is more active than its soluble counterpart molecules [25]. The PLGF-2 aa123-144 peptide enhances the function of several growth factors through its extraordinarily strong interaction with extracellular matrix components [26]. Using a cell binding assay, we demonstrate in this study that the Jurkat-binding peptide promotes the binding of the interferon to the cell membrane receptor (Fig. 6).

It should be noted that this is a proof-of-concept study launched to examine the role of the synthetic IFNP in vitro. A lentivirus vector system was used to deliver IFNP to Jurkat $\mathrm{T}$ lymphocyte leukemia cells. It will be important to determine whether the purified IFNP recombinant proteins are able to potentiate the antitumor activity. Thus, future studies are needed to validate the antitumor activity of IFNP, particularly when delivered in the form of purified recombinant proteins. Equally important is to demonstrate its antitumor activity in an animal xenograft tumor model using a commercial IFN $\alpha$ cytokine as the control.

The STAT pathway plays a critical role in the anti-infection of interferons [27-30]. IFN $\alpha$ exerts its anti-tumor/anti-viral responses by inducing both apoptotic and non-apoptotic cell death through the activation of intrinsic and extrinsic pathways [31-33]. IFN $\alpha$ binds to its surface receptor and initiates a cascade of events that induces the phosphorylation of JAK1 and TYK2 kinases, followed by the activation of the signal transducer and activation of transcription (STAT) family transcription factors [34, 35]. After activation, the STAT complex is subsequently translocated to the nucleus, where it induces transcription of genes related to cell-cycle arrest and apoptosis [36, 37]. In this study, we demonstrate that the Jurkat-binding peptide promotes the binding of IFN $\alpha$ to the membrane receptor (Fig. 6) and upregulates the downstream genes that are associated with the STAT1 and apoptosis pathways (Figs.4, 5). Thus, our data suggest that this short peptide may coordinate with IFN $\alpha$, spatially regulating the signaling of the interferon in the cytokine cascade pathway. It would also be interesting to examine if the alteration of the signal pathway, using reagents as previously reported [3841], will affect the therapeutic antitumor activity of the synthetic IFNP.

In summary, using phage library screening, we have identified a short peptide that specifically binds to Jurkat T lymphocyte leukemia cells. Fusion of this short peptide to the $\mathrm{C}$-terminus of IFN $\alpha$ significantly potentiates the antitumor activity. By promoting the binding of IFN $\alpha$ to the cell membrane receptor and spatially regulating the signaling of the interferon, the JBP peptide blocks Jurkat leukemia cells at the G0/G1 phase through the activation of the STAT1 and apoptosis pathways.

\section{Acknowledgements}

This work was supported by California Institute of Regenerative Medicine (CIRM) grant (RT2-01942), the National Natural Science Foundation of China grant (\#81272294, 


\section{Cellular Physiology Cell Physiol Biochem 2017;42:519-529 and Biochemistry Published online: June 02, $2017 \quad \begin{aligned} & \text { DO } 2017 \text { The Author(s). Published by S. Karger AG, Basel } \\ & \text { www.karger.com/cpb }\end{aligned}$ Yu et al.: Antitumor Activity of IFN $\alpha$-JBP}

\#31430021), the National Basic Research Program of China(973 Program)(\#2015CB943303) to J.F.H; the National Natural Science Foundation of China grant (\#81071920, \#81372835) and Jilin Science and Technique International Collaboration grant (\#20130413010GH) to W.L.; the Key Project of Chinese Ministry of Education (\#311015), the Bethune Program B (2012202) of the Jilin University, Jilin Provincial Science and Technology Department (20111807 and 20140414014GH, and 20150101176), the Platform Construction Project of Development and Reform Commission of Jilin Province (2014N147) to CJ; the National Natural Science Foundation of China grant (\#81302380) and Development Foundation for Youths of Jilin Provincial Science \& Technology Department grant (\#20140520017JH) to D.Y.

\section{Disclosure Statement}

The authors declare no competing financial interests.

\section{References}

1 Tsukasaki K, Tobinai K: Human T-cell lymphotropic virus type I-associated adult T-cell leukemialymphoma: new directions in clinical research. Clin Cancer Res 2014;20:5217-5125.

2 Fields PA, Taylor GP: "Antivirals" in the treatment of adult T cell leukaemia- lymphoma (ATLL). Curr Hematol Malig Rep 2012;7:267-275.

-3 Kato K, Akashi K: Recent Advances in Therapeutic Approaches for Adult T-cell Leukemia/Lymphoma. Viruses 2015;7:6604-6612.

4 Marcais A, Suarez F, Sibon D, Frenzel L, Hermine O, Bazarbachi A: Therapeutic options for adult T-cell leukemia/lymphoma. Curr Oncol Rep 2013;15:457-464.

-5 Yared JA, Kimball AS: Optimizing Management of Patients with Adult T Cell Leukemia-Lymphoma. Cancers (Basel) 2015;7:2318-2329.

6 Durinck K, Goossens S, Peirs S, Wallaert A, Van Loocke W, Matthijssens F, Pieters T, Milani G, Lammens T, Rondou P, Van Roy N, De Moerloose B, Benoit Y, Haigh J, Speleman F, Poppe B, Van Vlierberghe P: Novel biological insights in T-cell acute lymphoblastic leukemia. Exp Hematol 2015;43:625-639.

7 Bazarbachi A, Plumelle Y, Carlos Ramos J, Tortevoye P, Otrock Z, Taylor G, Gessain A, Harrington W, Panelatti G, Hermine O: Meta-analysis on the use of zidovudine and interferon-alfa in adult T-cell leukemia/ lymphoma showing improved survival in the leukemic subtypes. J Clin Oncol 2010;28:4177-4183.

8 Utsunomiya A, Choi I, Chihara D, Seto M: Recent advances in the treatment of adult T-cell leukemialymphomas. Cancer Sci 2015;106:344-351.

-9 Nasr R, El Hajj H, Kfoury Y, de The H, Hermine O, Bazarbachi A: Controversies in targeted therapy of adult T cell leukemia/lymphoma: ON target or OFF target effects? Viruses 2011;3:750-769.

10 Dasanu CA: Newer developments in adult T-cell leukemia/lymphoma therapeutics. Expert Opin Pharmacother 2011;12:1709-1717.

11 Ishitsuka K, Tsukasaki K, Tamura K: Interferon alfa and antiretroviral agents: a treatment option for adult T-cell leukemia/lymphoma. Drugs Today (Barc) 2011;47:615-623.

12 Yin H, Chen N, Guo R, Wang H, Li W, Wang G, Cui J, Jin H, Hu JF: Antitumor potential of a synthetic interferon-alpha/PLGF-2 positive charge peptide hybrid molecule in pancreatic cancer cells. Sci Rep 2015;5:16975.

13 Liu Y, Chen N, Yin H, Zhang L, Li W, Wang G, Cui J, Yang B, Hu JF: A placental growth factor-positively charged peptide potentiates the antitumor activity of interferon-gamma in human brain glioblastoma U87 cells. Am J Cancer Res 2016;6:214-225.

14 Li X, Mao C: Using phage as a platform to select cancer cell-targeting peptides. Methods Mol Biol 2014;1108:57-68.

15 Cao B, Yang M, Mao C: Phage as a Genetically Modifiable Supramacromolecule in Chemistry, Materials and Medicine. Acc Chem Res 2016;49:1111-1120.

16 Caberoy NB, Alvarado G, Bigcas JL, Li W: Galectin-3 is a new MerTK-specific eat-me signal. J Cell Physiol 2012;227:401-407.

17 Sun J, Li W, Sun Y, Yu D, Wen X, Wang H, Cui J, Wang G, Hoffman AR, Hu JF: A novel antisense long noncoding RNA within the IGF1R gene locus is imprinted in hematopoietic malignancies. Nucleic Acids Res 2014;42:9588-9601. 


\section{Cellular Physiology Cell Physiol Biochem 2017;42:519-529 \begin{tabular}{l|l} 
and Biochemistry Published online: June 02, 2017 & $\begin{array}{l}\text { (c) } 2017 \text { The Author(s). Published by S. Karger AG, Basel } \\
\text { www.karger.com/cpb }\end{array}$
\end{tabular}}

Yu et al.: Antitumor Activity of IFN $\alpha-J B P$

18 Wang H, Li W, Guo R, Sun J, Cui J, Wang G, Hoffman AR, Hu JF: An intragenic long noncoding RNA interacts epigenetically with the RUNX1 promoter and enhancer chromatin DNA in hematopoietic malignancies. Int J Cancer 2014;135:2783-2794.

19 Shi X, Li M, Cui M, Niu C, Xu J, Zhou L, Li W, Gao Y, Kong W, Cui J, Hu J, Jin H: Epigenetic suppression of the antitumor cytotoxicity of NK cells by histone deacetylase inhibitor valproic acid. Am J Cancer Res 2016;6:600-614.

20 Song W, Li W, Li L, Zhang S, Yan X, Wen X, Zhang X, Tian H, Li A, Hu JF, Cui J: Friend leukemia virus integration 1 activates the Rho GTPase pathway and is associated with metastasis in breast cancer. Oncotarget 2015;6:23764-23775.

-21 Kang L, Sun J, Wen X, Cui J, Wang G, Hoffman AR, Hu JF, Li W: Aberrant allele-switch imprinting of a novel IGF1R intragenic antisense non-coding RNA in breast cancers. Eur J Cancer 2015;51:260-270.

-22 Wang H, Chao K, Ng SC, Bai AH, Yu Q, Yu J, Li M, Cui Y, Chen M, Hu JF, Zhang S: Pro-inflammatory miR-223 mediates the cross-talk between the IL23 pathway and the intestinal barrier in inflammatory bowel disease. Genome Biol 2016;17:58.

23 Kinpara S, Kijiyama M, Takamori A, Hasegawa A, Sasada A, Masuda T, Tanaka Y, Utsunomiya A, Kannagi M: Interferon-alpha (IFN-alpha) suppresses HTLV-1 gene expression and cell cycling, while IFN-alpha combined with zidovudine induces p53 signaling and apoptosis in HTLV-1-infected cells. Retrovirology 2013;10:52.

24 Schultz GS, Davidson JM, Kirsner RS, Bornstein P, Herman IM: Dynamic reciprocity in the wound microenvironment. Wound Repair Regen 2011;19:134-148.

-25 Lortat-Jacob H, Esterre P, Grimaud JA: Interferon-gamma, an anti-fibrogenic cytokine which binds to heparan sulfate. Pathol Res Pract 1994;190:920-922.

26 Martino MM, Briquez PS, Guc E, Tortelli F, Kilarski WW, Metzger S, Rice JJ, Kuhn GA, Muller R, Swartz MA, Hubbell JA: Growth factors engineered for super-affinity to the extracellular matrix enhance tissue healing. Science 2014;343:885-888.

27 Szelag M, Piaszyk-Borychowska A, Plens-Galaska M, Wesoly J, Bluyssen HA: Targeted inhibition of STATs and IRFs as a potential treatment strategy in cardiovascular disease. Oncotarget 2016;7:48788-48812.

28 Merches K, Khairnar V, Knuschke T, Shaabani N, Honke N, Duhan V, Recher M, Navarini AA, Hardt C, Haussinger D, Tummler B, Gulbins E, Futerman AH, Hoffmann D, Lang F, Lang PA, Westendorf AM, Lang KS: Virus-Induced Type I Interferon Deteriorates Control of Systemic Pseudomonas Aeruginosa Infection. Cell Physiol Biochem 2015;36:2379-2392.

29 Heim MH, Thimme R: Innate and adaptive immune responses in HCV infections. J Hepatol 2014;61:S14-25.

-30 Zhu Y, Jia H, Chen J, Cui G, Gao H, Wei Y, Lu C, Wang L, Uede T, Diao H: Decreased Osteopontin Expression as a Reliable Prognostic Indicator of Improvement in Pulmonary Tuberculosis: Impact of the Level of Interferon-gamma-Inducible Protein 10. Cell Physiol Biochem 2015;37:1983-1996.

- 31 Thyrell L, Erickson S, Zhivotovsky B, Pokrovskaja K, Sangfelt O, Castro J, Einhorn S, Grander D: Mechanisms of Interferon-alpha induced apoptosis in malignant cells. Oncogene 2002;21:1251-1262.

-32 Booy S, Hofland L, van Eijck C: Potentials of interferon therapy in the treatment of pancreatic cancer. J Interferon Cytokine Res 2015;35:327-339.

-33 Barton C, Davies D, Balkwill F, Burke F: Involvement of both intrinsic and extrinsic pathways in IFNgamma-induced apoptosis that are enhanced with cisplatin. Eur J Cancer 2005;41:1474-1486.

-34 Zhao LJ, He SF, Liu Y, Zhao P, Bian ZQ Qi ZT: Inhibition of STAT Pathway Impairs Anti-Hepatitis C Virus Effect of Interferon Alpha. Cell Physiol Biochem 2016;40:77-90.

35 Takaoka A, Yanai H: Interferon signalling network in innate defence. Cell Microbiol 2006;8:907-922.

-36 Stark GR, Kerr IM, Williams BR, Silverman RH, Schreiber RD: How cells respond to interferons. Annu Rev Biochem 1998;67:227-264.

-37 Blouin CM, Lamaze C: Interferon gamma receptor: the beginning of the journey. Front Immunol 2013;4:267.

-38 Cafferkey C, Chau I: Novel STAT 3 inhibitors for treating gastric cancer. Expert Opin Investig Drugs 2016;25:1023-1031.

-39 Zhou Y, Zhang T, Wang X, Wei X, Chen Y, Guo L, Zhang J, Wang C: Curcumin Modulates Macrophage Polarization Through the Inhibition of the Toll-Like Receptor 4 Expression and its Signaling Pathways. Cell Physiol Biochem 2015;36:631-641.

40 Lai PS, Rosa DA, Magdy Ali A, Gomez-Biagi RF, Ball DP, Shouksmith AE, Gunning PT: A STAT inhibitor patent review: progress since 2011. Expert Opin Ther Pat 2015;25:1397-1421.

-41 Badr BM, Moustafa NA, Eldien HM, Mohamed AO, Ibrahim HM, El-Elaimy IA, Mahmoud MH, Badr G: Increased levels of type 1 interferon in a type 1 diabetic mouse model induce the elimination of $B$ cells from the periphery by apoptosis and increase their retention in the spleen. Cell Physiol Biochem 2015;35:137-147. 